\title{
Portal Vein Embolization: State-of-the-Art Technique and Options to Improve Liver Hypertrophy
}

\author{
Steven Y. Huang ${ }^{a}$ Thomas A. Aloia ${ }^{b}$ \\ a Department of Interventional Radiology, The University of Texas MD Anderson Cancer Center, Houston, TX, USA; \\ ${ }^{b}$ Department of Surgical Oncology, The University of Texas MD Anderson Cancer Center, Houston, TX, USA
}

\section{Keywords}

PVE · Technique · Adjunctive options

\section{Summary}

Portal vein embolization (PVE) is associated with a high technical and clinical success rate for induction of future liver remnant hypertrophy prior to surgical resection. The degree of hypertrophy is variable and depends on multiple factors, including technical aspects of the procedure and underlying chronic liver disease. For patients with insufficient liver volume following PVE, adjunctive techniques, such as intra-portal administration of stem cells, dietary supplementation, transarterial embolization, and hepatic vein embolization, are available. Our purpose is to review the state-of-the-art technique associated with high-quality PVE and to discuss options to improve hypertrophy of the future liver remnant.

(C) 2017 S. Karger GmbH, Freiburg

\section{Introduction}

Postoperative liver insufficiency is a severe, life-threatening complication following surgical resection for primary and secondary liver cancer. The mortality following major liver resection ranges from 3.2 to $7 \%$ for patients with non-injured liver and up to $32 \%$ for patients with cirrhosis [1-3]. Most cases of mortality can be attributed to postoperative liver failure, which is related to the size and function of the liver remnant [4]. Preoperative portal vein embolization (PVE) increases the size of the future liver remnant (FLR) and is associated with an overall morbidity of $21.7 \%$ and an overall mortality of $3.3 \%$ following major liver resection [5]. PVE induces sufficient liver hypertrophy to allow $78-80 \%$ of patients to undergo major hepatectomy $[6,7]$. The main causes of patient dropout following PVE are disease progression, medical comorbidities, and insufficient hypertrophy. The frequency of insufficient hypertrophy precluding definitive resection is only $0.6-3.6 \%$ $[6,7]$. In these few cases, there are options to stimulate additional liver growth. Our purpose is to review the state-of-the-art technique associated with high-quality PVE and to discuss options to improve hypertrophy of the FLR.

\section{State-of-the-Art Technique for High-Quality Portal Vein Embolization}

\section{Planning}

Prior to performing PVE, multiple patient factors should be considered to optimize FLR growth. The degree of liver hypertrophy is affected by chronic liver disease $[8,9]$. Thus, for some cases (e.g. patients with liver cirrhosis needing 40\% FLR), optimal hypertrophy may require an adjunctive procedure, such as sequential transarterial embolization (TAE) and PVE to achieve sufficient hypertrophy (see chapter on 'Sequential TAE and PVE'). In addition to underlying liver disease, preoperative chemotherapy for patients with colorectal liver metastases induces agent-specific toxicities to the liver that affect patient outcomes [10]. While the effects of fluorouracil, oxaliplatin, and irinotecan on morbidity and mortality following major liver surgery have been reported [11-13], their impact on the efficacy of PVE to induce FLR hypertrophy is less certain. In 2006, Beal et al. [14] showed that oxaliplatin-based chemotherapy administered in the interval between PVE and resection impaired liver regeneration $(\mathrm{p}=0.016)$. Additional recent studies by Goere et al. [15], Covey et al. [16], and Tanaka et al. [17] showed that chemotherapy did not impair liver hypertrophy. Thus, while surgeons may choose to withhold chemotherapy 4-6 weeks prior to resection to mitigate the risks posed by hepatotoxic chemotherapy to postoperative liver function, the published literature suggests that there is no significant effect upon liver regeneration following PVE.

\section{KARGER}

(๑) 2017 S. Karger GmbH, Freiburg 


\section{Technique}

PVE can be performed with intravenous moderate sedation or general anesthesia. There is no consensus on the use of prophylactic antibiotics. If an antibiotic is administered, a single dose can be administered within $1 \mathrm{~h}$ of the procedure. A common choice is ceftriaxone ( $1 \mathrm{~g}$ intravenous) or vancomycin $(15 \mathrm{mg} / \mathrm{kg})$ if the patient is penicillin-allergic. Unlike TAE, there have been no reports of patients with prior biliary manipulation who develop an abscess following PVE.

PVE can be performed via a surgical transileocolic or percutaneous transhepatic approach. In a meta-analysis, Abulkhir et al. [18] found that the FLR hypertrophy was significantly higher using the transhepatic technique with no significant difference in major complications. Percutaneous ultrasound-guided transhepatic access into the portal system can be performed from the contralateral or ipsilateral side of the liver to be resected [19]. Advantages of contralateral liver access (i.e. access through the FLR) are i) ease of manipulating the catheter into the right liver lobe, ii) deployment of embolic material in the direction of portal blood flow, and iii) avoidance of puncturing tumors in the right hepatic lobe. Disadvantages include difficulty with maneuvering a catheter into the anterior branches of S4 and potential injury to the FLR. The technical challenge of embolization of the right portal vein branches from a peripheral right portal vein access can be mitigated with the use of reverse-curve catheters (e.g. SOS-2 Omni ${ }^{\circledR}$ Catheter, AngioDynamics, Queensbury, NY, USA). It should be noted that studies by Ribero et al. [20] and Di Stefano et al. [21] showed no difference in the type or rates of complications between contralateral or ipsilateral liver access.

The nuances of our technique for PVE at The University of Texas MD Anderson Cancer Center have been previously described [22]. In brief, access to a peripheral branch of the ipsilateral portal system can be obtained with ultrasound guidance. Following placement of a 6-French vascular sheath, an Omni ${ }^{\mathrm{TM}}$ flush catheter (AngioDynamics) is placed at the splenic vein-superior mesenteric vein confluence. Venogram is performed in the anterior-posterior, oblique, and craniocaudal projections to delineate the S4 portal veins as well as separate the anterior and posterior right portal vein branches. Measurement of portal pressures should be performed as this may influence the decision of whether to operate. Patients with portosystemic gradients $>12 \mathrm{~mm} \mathrm{Hg}$ are at major risk of perisurgical complications [23-25]. PVE should increase the portosystemic gradient by $3 \mathrm{~mm} \mathrm{Hg}$ [23]. However, the effect of increased portal pressures following PVE on FLR hypertrophy, surgical outcomes, and evolution of portal hypertension is unclear.

PVE has been successfully performed with multiple agents either alone or in combination: particulates (i.e., polyvinyl alcohol (PVA) or trisacryl gelatin microspheres), n-butyl cyanoacrylate (NBCA), absorbable gelatin, ethanol, fibrin glue, and sclerosants (e.g. Aethoxysclerol/air-foam) [5]. Embolization should be permanent and as far distal as possible. Proximal embolization with coils without more distal particulate or liquid embolization allows intraparenchymal shunts to develop and limits FLR hypertrophy [22]. Of the various embolic agents, absorbable gelatin is associated with portal venous recanalization as early as 2 weeks following embolization $[19,26]$. In a report of 44 patients, Madoff et al. [27] found larger FLR hypertrophy following right portal vein embolization (RPVE) extended to segment 4 (RPVE+4) with trisacryl microspheres $(100-700 \mu \mathrm{m})$ when compared with PVA particles (355$1,000 \mu \mathrm{m})$. The two most commonly used agents used for portal venous occlusion are i) trisacryl microspheres with coil occlusion of the proximal right portal vein trunk and ii) NBCA (Histoacryl ${ }^{\circledR}$, B Braun, Melsungen, Germany) mixed with ethiodized oil (Lipiodol $^{\circledR}$, Guerbet, Roissy, France). When performing particulate embolization with trisacryl microspheres, most surgeons will start with $100-300 \mu \mathrm{m}$ particles, increasing in a stepwise fashion to 500 $700 \mu \mathrm{m}$ particles as hepatopedal flow is reduced. Coils are then placed at the origin of the segmental portal veins. Coil or vascular plug occlusion of the main right portal vein is an acceptable alternative to segmental venous coil occlusion so long as the operator can preserve at least $1 \mathrm{~cm}$ of patent right portal vein to facilitate surgical ligation. NBCA embolization involves injection of small aliquots of NBCA mixed with ethiodized oil in ratios of 1:2-1:8 with copious intermittent flushing using a nonionic solution such as $5 \%$ dextrose to prevent premature NBCA polymerization [22, 28]. In practice, a 1-3 ml syringe containing the NBCA mixed with ethiodized oil is connected to a 3-way stopcock in addition to a $20 \mathrm{ml}$ syringe containing $5 \%$ dextrose. The main advantages of NBCA embolization are shorter procedure times, permanent aggressive distal embolization, and lower cost. It should be noted that NBCA induces a strong inflammatory response which can make resection more technically challenging [19]. Many embolic agents have been used to successfully increase the size of the FLR. Operator familiarity and experience with the embolic agent is of utmost importance to ensure precise delivery and preservation of non-targeted branches.

RPVE should be readily extended to segment 4 portal veins (RPVE+4) to enhance the degree of hypertrophy for segments 2 and 3. In a study of 73 patients who underwent RPVE $(n=15)$ or RPVE $+4(n=58)$, volumes of segments 2 and 3 increased more in the RPVE+4 group (mean $141 \mathrm{ml}$ for RPVE+4 compared to $106 \mathrm{ml}$ for RPVE alone; $p=0.044$ ). No significant differences between complication rates were identified [29]. Prior to embolization of segment 4, dedicated left portal venogram should be performed to delineate anatomy and patency. From an ipsilateral approach, segment 4 embolization is performed prior to RPVE as manipulating a catheter through an embolized right liver could cause dislodgement of embolic particles. Catheterization of segment 4 is performed with a Cobra- 2 catheter (AngioDynamics). To prevent reflux of particles into the FLR, distal embolization is performed through a microcatheter. Alternatively, a balloon occlusion catheter can also be used to prevent reflux into the FLR (fig. 1). Coil embolization is then performed with pushable or detachable 0.018 " microcoils (VortX, Interlock-18, Boston Scientific, Malborough, MA, USA). Operators who perform RPVE with NBCA mixed with ethiodized oil will often use particles and coils to embolize S4 branches because of the increased control offered by these agents.

The embolization endpoint for PVE should be complete stasis. 
Fig. 1. 60-year-old female with cholangiocarcinoma presenting for right portal vein embolization extended to segment 4 portal veins. A balloon occlusion catheter (Fogarty ${ }^{\circledR}$, Edwards Lifesciences, Irvine, CA, USA) is placed in segment $4 \mathrm{~A}$ (white arrow). Injection of contrast demonstrates patent antegrade flow and no reflux. Image courtesy of Armeen Mahvash, MD.

Termination of embolization prior to this endpoint incurs the risk of incomplete embolization and vessel recanalization, which limits hypertrophy (fig. 2). Assessment of stasis can be performed with portal venography. Theoretically, performing a post embolization venogram from an ipsilateral access requires manipulation of a catheter through the embolized lobe. In our practice, we generally advance the reverse-curve catheter used for particulate and coil embolization of the right portal vein into the main portal vein without changing to a multi-sidehole catheter. This allows for completion venography and measurement of post-embolization portal pressures while mitigating the risk associated with catheter manipulation and exchange.

\section{Complications}

In a large review of 1,179 patients who underwent PVE, van Lienden et al. [5] calculated a procedural-related mortality of $0.1 \%$ and a major complication rate of $0.4 \%$. Major complications included vascular injury, biloma, infection, non-target embolization, portal/mesenteric venous thrombosis, and portal hypertension. Minor complications were generally self-limited and included fever (36.9\%), elevation of transaminases (34.8\%), abdominal discomfort/pain (22.9\%), nausea/vomiting (2.0\%), and ileus (1.2\%).

\section{Options to Improve Future Liver Remnant Hypertrophy}

\section{Intra-Portal Administration of Stem Cells}

To improve FLR hypertrophy following PVE, Schulte am Esch et al. [30] performed a study on 22 patients comparing PVE in combination with simultaneous administration of CD133+ bone marrow stem cells versus PVE alone. The authors found an absolute gain of $138.66 \pm 66.29 \mathrm{ml}$ in the PVE and stem cell group compared with $62.95 \pm 40.03 \mathrm{ml}$ in the PVE alone group ( $\mathrm{p}=0.004)$. These results corroborated an earlier pilot study conducted by Fürst et al. [31] in which the relative gain in FLR volume for patients administered stem cells following PVE $(n=6)$ was $77.3 \pm$
Fig. 2. 59-year-old male with metastatic colorectal carcinoma presenting for right portal vein embolization extended to segment 4 portal veins (RPVE+4) prior to extended right hepatectomy. A Completion portal venogram following embolization demonstrates sluggish but patent flow in 3 branches supplying segment 6 (black arrows). B Coronal maximum intensity projection image from a computed tomography scan performed 30 days following RPVE+4 demonstrates patent flow involving 3 branches supplying segment 6 (black arrows).

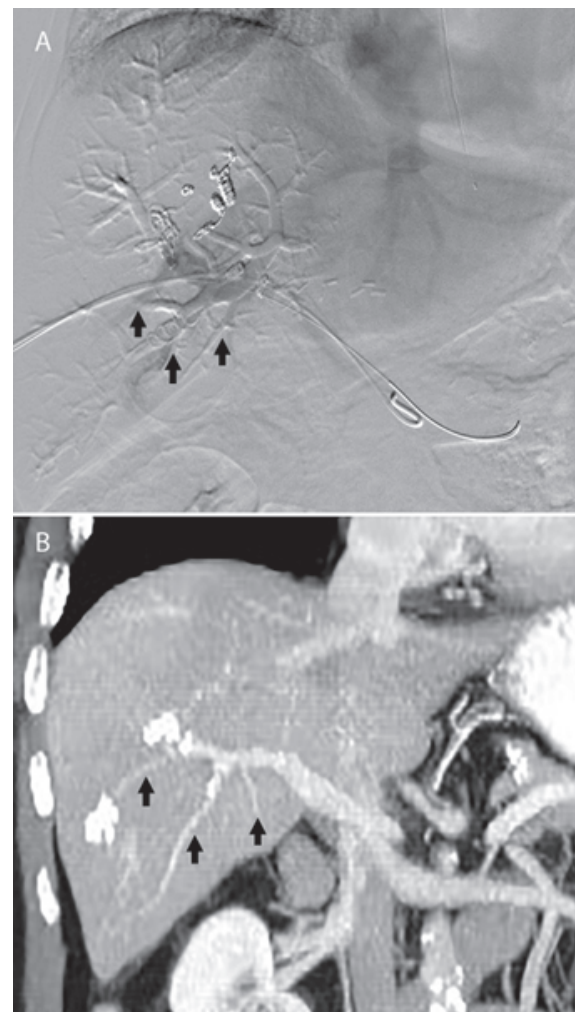

$38.2 \%$ compared with $39.1 \pm 20.4 \%$ for patients following PVE alone $(n=7)(p=0.039)$. While the data is encouraging, several issues should be investigated prior to widespread adoption. The efficacy of this technique in patients with diabetes mellitus, chronic liver disease, and prolonged chemotherapy is unknown. There is also the possibility that administration of bone marrow stem cells may enhance tumor progression [32].

\section{Dietary Supplementation}

Dietary supplementation to improve the hypertrophic effect of PVE is an area of active research. In a preclinical study using New Zealand White rabbits, Olthof et al. [33] found that administration of obeticholic acid (OCA, potent farnesoid X receptor agonist) in addition to PVE resulted in FLR hypertrophy of $56.1 \pm 20.3 \%$ compared to $26.1 \pm 15.4 \%$ for control animals who underwent PVE only $(\mathrm{p}<0.001)$. The number of Ki-67-positive hepatocytes was 1.6-fold higher in the animals administered OCA ( $\mathrm{p}=0.045)$, indicating a stronger hyperplastic hepatocyte response. Beppu et al. [34] conducted a small randomized clinical study in which one cohort $(\mathrm{n}=13)$ was administered branched-chain amino acid dietary supplements (LIVACT ${ }^{\circledR}$, Ajinomoto, Tokyo, Japan) before PVE and continued for 6 months following liver resection compared to another cohort $(\mathrm{n}=15)$ who underwent PVE without dietary supplementation. Functional liver regeneration was assessed by liver uptake on Technetium-99m (Tc-99m) galactosyl human serum albumin scintigraphy. The authors found that the liver uptake value increased $266.7 \%$ in the branched-chain amino acid + PVE group compared to $77.6 \%$ for the PVE alone group $(\mathrm{p}=0.04)$. While ad- 
Table 1. Studies evaluating the effect of sequential transarterial chemoembolization (TACE) followed by portal vein embolization (PVE)

\begin{tabular}{|c|c|c|c|c|c|c|}
\hline Study [ref.] & $\mathrm{n}$ & Tumor & TACE technique & $\begin{array}{l}\text { Time interval } \\
\text { between TACE } \\
\text { and PVE, weeks }\end{array}$ & $\begin{array}{l}\text { FLR } \\
\text { hypertrophy, } \\
\%\end{array}$ & $\begin{array}{l}\text { Complications } \\
\text { following } \\
\text { TACE/PVE }\end{array}$ \\
\hline Yamakado et al. [51] & 7 & HCC & TACE with ethiodized oil & $2-6$ & $56.7 \pm 21.6^{\mathrm{a}}$ & NA \\
\hline Aoki et al. [36] & 17 & $\mathrm{HCC}$ & TACE with ethiodized oil & $1-1.5$ & $51(39-68)^{b}$ & $5^{c}$ \\
\hline Ogata et al. [35] & 18 & $\mathrm{HCC}$ & TACE with ethiodized oil & $3-6$ & $12 \pm 5^{\mathrm{a}}$ & none \\
\hline Peng et al. [52] & 29 & multiple & $\begin{array}{l}\text { i) TACE with ethiodized oil } \\
\text { ii) drug-eluting beads }\end{array}$ & $8.6(4-14.6)^{b}$ & $7.4(2.2-11.6)^{\mathrm{b}}$ & $1^{\mathrm{d}}$ \\
\hline
\end{tabular}

${ }^{a}$ Mean \pm standard deviation.

${ }^{b}$ Median (range).

'Included cholecystitis, pleural effusion, asthma attack, ascites, and bowel obstruction.

${ }^{\mathrm{d}}$ Included abscess following arterial embolization.

FLR $=$ Future liver remnant HCC $=$ hepatocellular carcinoma; NA = not applicable. ditional research is needed, dietary supplementation is an intriguing field which may improve the hypertrophic and functional response of the FLR following PVE.

\section{Sequential TAE and PVE}

PVE reproducibly increases the size of the FLR though the degree of hypertrophy is variable, especially in patients with chronic liver disease [3]. Furthermore, for patients with hepatocellular carcinoma (HCC) and liver cirrhosis, arterioportal shunts in tumors may attenuate the hypertrophic effect of PVE. It has been shown that sequential TAE followed by PVE increases the rate of FLR hypertrophy more than PVE alone (table 1). The benefits of this dual technique are improved FLR hypertrophy relative to PVE alone and induction of an anti-tumor effect in the embolized lobe [35, 36]. For safety purposes, tumor embolization should be performed as far distally as possible, and liver functional tests should be allowed to normalize prior to PVE. Despite this cautious approach, Aoki et al. [36] demonstrated areas of segmental infarction within noncancerous liver of resected liver specimens. While embolization of the hepatic artery prior to PVE is an effective adjunctive technique, it should be performed carefully, since many of these patients have pre-existing liver dysfunction.

\section{Sequential PVE and TAE}

Definitive hepatectomy following PVE may not be possible because of disease progression, medical comorbidities, and insufficient hypertrophy of the FLR. For patients with HCC, TAE may be the next therapeutic option. A prior report by Kang et al. [37] showed that PVE followed by subselective TAE is a safe and effective technique to treat HCC. In addition to locoregional management of liver cancer, several small studies postulate that subsequent arterial embolization following PVE may further augment FLR hypertrophy [38-41]. Inaba et al. [39] found a change in FLR of 1.4 times that of the original level for combined PVE followed by TAE ( $\mathrm{n}=4$ patients) compared to a change in FLR of 1.3 times that of the original level for the PVE-only group $(n=6)$. As expected, sequential PVE followed by TAE is associated with hepatic infarction and abscess formation $[37,38,41]$. To mitigate these risks, op- erators need to consider the type of embolic material, territory of embolization, and embolization endpoint carefully. The data currently available do not support any particular regimen. It is imperative that patients who undergo this sequential procedure be carefully selected and monitored following embolization.

\section{Sequential PVE and Hepatic Vein Embolization}

Hepatic vein embolization (HVE) following PVE induces further damage to the embolized lobe by increasing outflow obstruction, which obstructs arterial inflow and further decreases any residual portal blood flow. Hwang et al. [42] demonstrated the initial safety and efficacy of this technique in 12 patients with hepatobiliary malignancy. Because of insufficient FLR hypertrophy following RPVE, patients underwent right HVE (fig. 3). A vascular plug was placed at the central portion of the right hepatic vein, and all sizeable branches were embolized with coils. In a subsequent study, Hwang et al. [43] treated 42 patients over an 8-year period with insufficient FLR hypertrophy following PVE with adjunctive HVE. $33(78.6 \%)$ of the patients had cholangiocarcinoma. The degree of FRL hypertrophy for this cohort was $13.3 \%$ following PVE and 28.9\% following PVE-HVE. There were no procedural-related complications. As expected, histologic examination of the liver from resected specimens showed increased apoptosis in areas affected by both PVE and HVE compared to areas affected by PVE alone $[42,43]$. Though the current clinical experience is limited, HVE following PVE appears to be effective and well-tolerated by patients with insufficient FLR hypertrophy following PVE.

\section{Simultaneous PVE and HVE (Liver Venous Deprivation)}

Liver venous deprivation (LVD) builds upon the earlier work by Hwang et al. [43]. The technique involves RPVE and embolization of the right and/or middle hepatic vein during the same procedure. An initial pilot study involving 7 patients by Guiu et al. [44] reported an FLR increase from 28.2\% (range 22.4-33.3\%) to $40.9 \%$ (range 33.6-59.3\%) at 23 days following LVD. In a follow-up study of 10 patients, FLR volume increased by $53.4 \%$ as early as 7 days following LVD. Liver function as measured by Tc-99m mebrofenin hepatobiliary scintigraphy increased by $64.3 \%$ (range $28.1-107.5 \%$ ) 
Fig. 3. 50-year-old male with metastatic colon cancer to the liver status post 1st-stage segment 3 liver resection presenting for right portal vein embolization (RPVE) prior to 2nd-stage right hepatectomy. A Axial computed tomography (CT) image demonstrates the future liver remnant (FLR, outlined by white dots) measuring $511 \mathrm{ml}$. B Patient underwent RPVE with trisacryl gelatin microspheres and coils. Completion portal venogram demonstrates successful occlusion of the right portal vein branches. C Axial CT image obtained 21 days following PVE demonstrates slight increase in FLR volume to $579 \mathrm{ml}$. D Patient underwent adjunctive right hepatic vein embolization (HVE) with coils and vascular plugs. Completion venogram demonstrates occlusion of the right hepatic

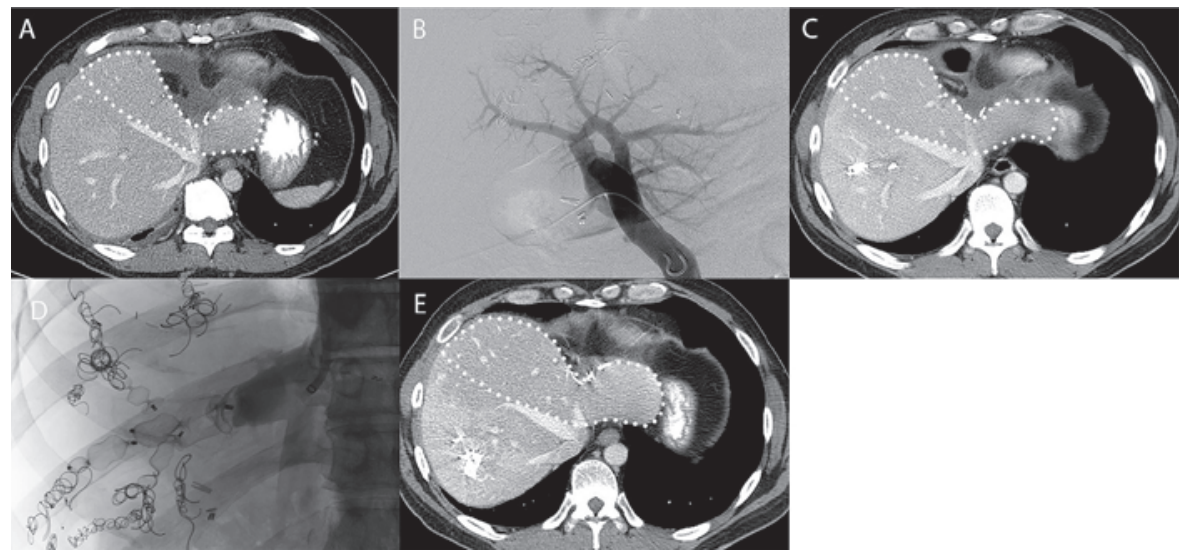
vein. E Axial CT image from a CT scan obtained 57 days following HVE demonstrates interval increase in FLR volume to $740 \mathrm{ml}$

at day 21. The procedure was relatively well-tolerated. Patients complained of fatigue $(n=2)$, fever $(n=3)$, and pain for $24 \mathrm{~h}(\mathrm{n}=$ 6). Histology in the embolized lobe revealed sinusoidal dilatation, hepatocyte necrosis, and atrophy [45]. In another small study involving 7 patients, Le Roy et al. [46] found a mean FLR hypertrophy rate of $52.6 \%$ (range 18.2-187.9\%) following LVD. There were no postprocedural complications. To date, there have been 17 published patients who have undergone LVD, and 3 (17.6\%) patients did not undergo surgical resection. 2 patients experienced interval disease progression, and 1 patient had insufficient FLR hypertrophy. No patients who underwent surgery developed postoperative liver failure [44-46]. While these early results with LVD are encouraging, comparison studies are necessary to evaluate the additional benefit provided by simultaneous PVE and HVE.

\section{Sequential PVE and Parenchymal Liver Transection \\ ('Salvage' ALPPS)}

'Salvage' ALPPS (associating liver partition and portal vein ligation for staged hepatectomy) involves parenchymal transection along the FLR margin. This procedure has been reported for patients with insufficient FLR hypertrophy following PVE [47-49]. Mean FLR hypertrophy after sequential PVE and ALPPS ranges from 57 to $65 \%[48,49]$. A recent consensus statement from an international expert meeting on ALPPS recommended that adjunctive ALPPS can be considered for patients with insufficient hypertrophy following PVE.

There are no prospective randomized clinical studies to prove the efficacy of PVE to prevent post-resection liver insufficiency or failure. As a result, physicians' knowledge and attitudes towards PVE are formed largely from retrospective data and personal experience. In a multinational study involving 54 institutions, Day et al. [50] found significant variability in surgeons' utilization of and at- titudes towards PVE for FLR hypertrophy. Institutions capable of performing high-quality PVE (i.e. RPVE +4 and embolization with a permanent embolic agent such as trisacryl microspheres) were significantly associated with the subjective impression of a higher likelihood of FLR hypertrophy. The authors postulate that institutions without access to high-quality PVE are more likely to turn to the ALPPS procedure. Thus, it is important that for each case of insufficient FLR hypertrophy, the technique and materials used during PVE should be re-evaluated to assess whether liver growth was suboptimal because of technique or an intrinsic problem of liver regeneration. Research focused on patient selection will help to ensure that patients are provided upfront with the safest and most effective modality to maximize FLR hypertrophy.

\section{Conclusion}

PVE has improved the safety profile for patients who undergo partial hepatectomy for more than 20 years. The technical and clinical success rate of PVE for the induction of FLR hypertrophy is high $[6,7]$. Nonetheless, the degree of hypertrophy among patients is variable and may depend on multiple factors, including technical aspects of the procedure and underlying chronic liver disease. Adjunctive techniques to further improve FLR hypertrophy are becoming more prevalent. These interventions will continue to improve patient safety while eliminating cases of insufficient liver hypertrophy.

\section{Disclosure Statement}

The authors S.Y.H. and T.A.A. report no conflict of interests. 


\section{References}

1 Broering DC, Hillert C, Krupski G, Fischer L, Mueller L, Achilles EG, Schulte am Esch J, Rogiers X: Portal vein embolization vs. portal vein ligation for induction of hypertrophy of the future liver remnant. J Gastrointest Surg 2002;6:905-913; discussion 913.

$\checkmark 2$ Hemming AW, Reed AI, Howard RJ, Fujita S, Hochwald SN, Caridi JG, Hawkins IF, Vauthey JN: Preoperative portal vein embolization for extended hepatectomy. Ann Surg 2003;237:686-691; discussion 691-693.

3 Farges O, Belghiti J, Kianmanesh R, Regimbeau JM, Santoro R, Vilgrain V, Denys A, Sauvanet A: Portal vein embolization before right hepatectomy: prospective clinical trial. Ann Surg 2003;237:208-217.

4 Yamanaka N, Okamoto E, Kuwata K, Tanaka N: A multiple regression equation for prediction of posthepatectomy liver failure. Ann Surg 1984;200:658-663.

$\checkmark 5$ Van Lienden KP, van den Esschert JW, de Graaf W, Bipat S, Lameris JS, van Gulik TM, van Delden OM: Portal vein embolization before liver resection: a systematic review. Cardiovasc Intervent Radiol 2013;36: 25-34.

6 Yamashita S, Sakamoto Y, Yamamoto S, Takemura N, Omichi K, Shinkawa H, Mori K, Kaneko J, Akamatsu N, Arita J, Hasegawa K, Kokudo N: Efficacy of preoperative portal vein embolization among patients with hepatocellular carcinoma, biliary tract cancer, and colorectal liver metastases: a comparative study based on single-center experience of 319 cases. Ann Surg Oncol 2017;24:1557-1568

7 Shindoh J, Tzeng CW, Aloia TA, Curley SA, Huang SY, Mahvash A, Gupta S, Wallace MJ, Vauthey JN: Safety and efficacy of portal vein embolization before planned major or extended hepatectomy: an institutional experience of 358 patients. J Gastrointest Surg 2014;18:45-51.

8 Azoulay D, Castaing D, Krissat J, Smail A, Hargreaves GM, Lemoine A, Emile JF, Bismuth H: Percutaneous portal vein embolization increases the feasibility and safety of major liver resection for hepatocellular carcinoma in injured liver. Ann Surg 2000;232:665-672.

9 Tanaka H, Hirohashi K, Kubo S, Shuto T, Higaki I, Kinoshita H: Preoperative portal vein embolization improves prognosis after right hepatectomy for hepatocellular carcinoma in patients with impaired hepatic function. Br J Surg 2000;87:879-882.

10 Zorzi D, Laurent A, Pawlik TM, Lauwers GY, Vauthey JN, Abdalla EK: Chemotherapy-associated hepatotoxicity and surgery for colorectal liver metastases. Br J Surg 2007;94:274-286.

11 Vauthey JN, Pawlik TM, Ribero D, Wu TT, Zorzi D, Hoff PM, Xiong HQ, Eng C, Lauwers GY, MinoKenudson M, Risio M, Muratore A, Capussotti L, Curley SA, Abdalla EK: Chemotherapy regimen predicts steatohepatitis and an increase in 90-day mortality after surgery for hepatic colorectal metastases. J Clin Oncol 2006;24:2065-2072.

12 Karoui M, Penna C, Amin-Hashem M, Mitry E, Benoist S, Franc B, Rougier P, Nordlinger B: Influence of preoperative chemotherapy on the risk of major hepatectomy for colorectal liver metastases. Ann Surg 2006;243:1-7.

13 Nakano H, Oussoultzoglou E, Rosso E, Casnedi S, Chenard-Neu MP, Dufour P, Bachellier P, Jaeck D: Sinusoidal injury increases morbidity after major hepatectomy in patients with colorectal liver metastases receiving preoperative chemotherapy. Ann Surg 2008; 247:118-124.

14 Beal IK, Anthony S, Papadopoulou A, Hutchins R, Fusai G, Begent R, Davies N, Tibballs J, Davidson B: Portal vein embolisation prior to hepatic resection for colorectal liver metastases and the effects of periprocedure chemotherapy. Br J Radiol 2006;79:473-478.
5 Goere D, Farges O, Leporrier J, Sauvanet A, Vilgrain V, Belghiti J: Chemotherapy does not impair hypertrophy of the left liver after right portal vein obstruction. J Gastrointest Surg 2006;10:365-370.

16 Covey AM, Brown KT, Jarnagin WR, Brody LA, Schwartz L, Tuorto S, Sofocleous CT, D’Angelica M, Getrajdman GI, DeMatteo R, Kemeny NE, Fong Y: Combined portal vein embolization and neoadjuvant chemotherapy as a treatment strategy for resectable hepatic colorectal metastases. Ann Surg 2008;247:451455.

17 Tanaka K, Kumamoto T, Matsuyama R, Takeda K, Nagano Y, Endo I: Influence of chemotherapy on liver regeneration induced by portal vein embolization or first hepatectomy of a staged procedure for colorectal liver metastases. J Gastrointest Surg 2010;14:359-368.

18 Abulkhir A, Limongelli P, Healey AJ, Damrah O, Tait P, Jackson J, Habib N, Jiao LR: Preoperative portal vein embolization for major liver resection: a meta-analysis. Ann Surg 2008;247:49-57.

19 De Baere T, Roche A, Elias D, Lasser P, Lagrange C, Bousson V: Preoperative portal vein embolization for extension of hepatectomy indications. Hepatology 1996;24:1386-1391.

20 Ribero D, Abdalla EK, Madoff DC, Donadon M, Loyer EM, Vauthey JN: Portal vein embolization before major hepatectomy and its effects on regeneration, resectability and outcome. Br J Surg 2007;94:1386-1394.

21 Di Stefano DR, de Baere T, Denys A, Hakime A, Gorin G, Gillet M, Saric J, Trillaud H, Petit P, Bartoli JM, Elias D, Delpero JR: Preoperative percutaneous portal vein embolization: evaluation of adverse events in 188 patients. Radiology 2005;234:625-630.

22 De Baere T, Denys A, Madoff DC: Preoperative portal vein embolization: indications and technical consider ations. Tech Vasc Interv Radiol 2007;10:67-78.

23 Denys A, Bize P, Demartines N, Deschamps F, De Baere T; Cardiovascular and Interventional Radiological Society of Europe: Quality improvement for portal vein embolization. Cardiovasc Intervent Radiol 2010; 33:452-456.

24 Bruix J, Castells A, Bosch J, Feu F, Fuster J, GarciaPagan JC, Visa J, Bru C, Rodes J: Surgical resection of hepatocellular carcinoma in cirrhotic patients: prognostic value of preoperative portal pressure. Gastroenterology 1996;111:1018-1022.

25 Farges O, Malassagne B, Flejou JF, Balzan S, Sauvanet A, Belghiti J: Risk of major liver resection in patients with underlying chronic liver disease: a reappraisal. Ann Surg 1999;229:210-215.

26 Kusaka K, Imamura H, Tomiya T, Makuuchi M: Factors affecting liver regeneration after right portal vein embolization. Hepatogastroenterology 2004;51:532535.

27 Madoff DC, Abdalla EK, Gupta S, Wu TT, Morris JS, Denys A, Wallace MJ, Morello FA, Jr., Ahrar K, Murthy R, Lunagomez S, Hicks ME, Vauthey JN: Transhepatic ipsilateral right portal vein embolization extended to segment IV: improving hypertrophy and resection outcomes with spherical particles and coils. J Vasc Interv Radiol 2005; 16:215-225.

28 Giraudo G, Greget M, Oussoultzoglou E, Rosso E, Bachellier P, Jaeck D: Preoperative contralateral portal vein embolization before major hepatic resection is a safe and efficient procedure: a large single institution experience. Surgery 2008;143:476-482.

29 Kishi Y, Madoff DC, Abdalla EK, Palavecino M, Ribero D, Chun YS, Vauthey JN: Is embolization of segment 4 portal veins before extended right hepatectomy justified? Surgery 2008;144:744-751.
0 Schulte am Esch J, Schmelzle M, Fürst G, Robson SC, Krieg A, Duhme C, Tustas RY, Alexander A, Klein HM, Topp SA, Bode JG, Häussinger D, Eisenberger CF, Knoefel WT: Infusion of CD133+ bone marrow-derived stem cells after selective portal vein embolization enhances functional hepatic reserves after extended right hepatectomy: a retrospective single-center study. Ann Surg 2012;255:79-85.

31 Fürst G, Schulte am Esch J, Poll LW, Hosch SB, Fritz LB, Klein M, Godehardt E, Krieg A, Wecker B, Stoldt V, Stockschläder M, Eisenberger $\mathrm{CF}$, Mödder U, Knoefel WT: Portal vein embolization and autologous CD133+ bone marrow stem cells for liver regeneration: initial experience. Radiology 2007;243:171-179.

32 Audollent R, Eveno C, Contreres JO, Hainaud P, Rampanou A, Dupuy E, Brouland JP, Pocard M: Bone marrow-derived endothelial and hematopoietic precursors cells enhance the metastasis of colon cancer in an orthotopic murine model. Int J Cancer 2011;129: 2304-2305.

33 Olthof PB, Huisman F, Schaap FG, van Lienden KP, Bennink RJ, van Golen RF, Heger M, Verheij J, Jansen PL, Olde Damink SW, van Gulik TM: Effect of obeticholic acid on liver regeneration following portal vein embolization in an experimental model. Br J Surg 2017;104:590-599.

34 Beppu T, Nitta H, Hayashi H, Imai K, Okabe H, Nakagawa S, Hashimoto D, Chikamoto A, Ishiko T, Yoshida M, Yamashita Y, Baba H: Effect of branched-chain amino acid supplementation on functional liver regeneration in patients undergoing portal vein embolization and sequential hepatectomy: a randomized controlled trial. J Gastroenterol 2015;50:1197-1205.

35 Ogata S, Belghiti J, Farges O, Varma D, Sibert A, Vilgrain V: Sequential arterial and portal vein embolizations before right hepatectomy in patients with cirrhosis and hepatocellular carcinoma. Br J Surg 2006; 93:1091-1098.

36 Aoki T, Imamura H, Hasegawa K, Matsukura A, Sano K, Sugawara Y, Kokudo N, Makuuchi M: Sequential preoperative arterial and portal venous embolizations in patients with hepatocellular carcinoma. Arch Surg 2004;139:766-774.

37 Kang BK, Kim JH, Kim KM, Ko GY, Yoon HK, Gwon DI, Sung KB: Transcatheter arterial chemoembolization for hepatocellular carcinoma after attempted portal vein embolization in 25 patients. AJR Am J Roentgenol 2009;193:W446-451.

38 Nagino M, Kanai M, Morioka A, Yamamoto H, Kawabata Y, Hayakawa N, Nimura Y: Portal and arterial embolization before extensive liver resection in patients with markedly poor functional reserve. J Vasc Interv Radiol 2000;11:1063-1068.

- 39 Inaba S, Takada T, Amano H, Yoshida M, Yamakawa Y, Yasuda H, Takada Y, Takeshita K, Koutake H, Takada K, Furui S, Hijikata H, Takada K: Combination of preoperative embolization of the right portal vein and hepatic artery prior to major hepatectomy in high-risk patients: a preliminary report. Hepatogastroenterology 2000;47:1077-1081.

40 Gruttadauria S, Luca A, Mandala L, Miraglia R, Gridelli B: Sequential preoperative ipsilateral portal and arterial embolization in patients with colorectal liver metastases. World J Surg 2006;30:576-578.

41 Yokoyama Y, Nagino M: Sequential PVE and TAE for biliary tract cancer and liver metastases; in Madoff DC, Makuuchi M, Mizuno T, Vauthey J-N (eds): Venous Embolization of the Liver. Radiologic and Surgical Practice. London, Springer, 2011. 
42 Hwang S, Lee SG, Ko GY, Kim BS, Sung KB, Kim MH, Lee SK, Hong HN: Sequential preoperative ipsilateral hepatic vein embolization after portal vein embolization to induce further liver regeneration in patients with hepatobiliary malignancy. Ann Surg 2009;249:608-616.

43 Hwang S, Ha TY, Ko GY, Kwon DI, Song GW, Jung DH, Kim MH, Lee SK, Lee SG: Preoperative sequential portal and hepatic vein embolization in patients with hepatobiliary malignancy. World J Surg 2015;39:29902998.

44 Guiu B, Chevallier P, Denys A, Delhom E, PierredonFoulongne MA, Rouanet P, Fabre JM, Quenet F, Herrero A, Panaro F, Baudin G, Ramos J: Simultaneous trans-hepatic portal and hepatic vein embolization before major hepatectomy: the liver venous deprivation technique. Eur Radiol 2016;26:4259-4267.

45 Guiu B, Quenet F, Escal L, Bibeau F, Piron L, Rouanet P, Fabre JM, Jacquet E, Denys A, Kotzki PO, Verzilli D, Deshayes E: Extended liver venous deprivation before major hepatectomy induces marked and very rapid increase in future liver remnant function. Eur Radiol 2017;27:3343-3352.
46 Le Roy B, Perrey A, Fontarensky M, Gagniere J, Abergel A, Pereira B, Lambert C, Boyer L, Pezet D, Chabrot P, Buc E: Combined preoperative portal and hepatic vein embolization (biembolization) to improve liver regeneration before major liver resection: a preliminary report. World J Surg 2017;41:1848-1856.

47 Sparrelid E, Gilg S, Brismar TB, Lundell L, Isaksson B: Rescue ALPPS is efficient and safe after failed portal vein occlusion in patients with colorectal liver metastases. Langenbecks Arch Surg 2017;402:69-75.

48 Knoefel WT, Gabor I, Rehders A, Alexander A, Krausch M, Schulte am Esch J, Fürst G, Topp SA: In situ liver transection with portal vein ligation for rapid growth of the future liver remnant in two-stage liver resection. Br J Surg 2013;100:388-394.

49 Tschuor C, Croome KP, Sergeant G, Cano V, Schadde E, Ardiles V, Slankamenac K, Claria RS, de Santibanes E, Hernandez-Alejandro R, Clavien PA: Salvage parenchymal liver transection for patients with insufficient volume increase after portal vein occlusion - an extension of the ALPPS approach. Eur J Surg Oncol 2013;39: 1230-1235.
Day RW, Conrad C, Vauthey JN, Aloia TA: Evaluating surgeon attitudes towards the safety and efficacy of portal vein occlusion and associating liver partition and portal vein ligation: a report of the MALINSA survey. HPB (Oxford) 2015;17:936-941.

51 Yamakado K, Takeda K, Matsumura K, Nakatsuka A, Hirano T, Kato N, Sakuma H, Nakagawa T, Kawarada Y: Regeneration of the un-embolized liver parenchyma following portal vein embolization. J Hepatol 1997;27: 871-880.

52 Peng PD, Hyder O, Bloomston M, Marques H, Corona-Villalobos $\mathrm{C}$, Dixon E, Pulitano $\mathrm{C}$, Hirose $\mathrm{K}$, Schulick RD, Barroso E, Aldrighetti L, Choti M, Shen F, Kamel I, Geschwind JF, Pawlik TM: Sequential intra-arterial therapy and portal vein embolization is feasible and safe in patients with advanced hepatic malignancies. HPB (Oxford) 2012;14:523-531. 